\title{
Notes for the guidance of authors
}

Transactions of the Royal Society of Edinburgh: Earth Sciences appears quarterly, publishing original scientific research papers, reviews, short communications and letters on all fields of the earth sciences, such as: petrology, economic geology, geophysics, geochemistry, mineralogy, palaeontology, tectonics and structural geology, sedimentology, volcanology, geomorphology, Quaternary studies, palaeoclimatology, hydrogeology, soil science, oceanography, environmental geology, stratigraphy and related planetary sciences. Articles do not need to be concerned with Scottish earth science, neither are authors required to be Fellows of the Society. Articles should have relevance to a world-wide audience, even if the study is focussed on a single geographical site. Papers should make topical, substantial and scholarly contributions to mainstream knowledge via the addition of new methods, or approaches, or information or understanding. The editors are keen to encourage interdisciplinary papers as well as articles concerned with earth science processes and their modelling. Normally there is an upper limit of 25000 words, but most contributions are expected to be shorter. Discussions of articles previously published in the Transactions and reviews of topics of current interest are also invited. There are no page charges; however, if foldouts or colour illustrations are envisaged, the Editorial Office should be consulted prior to submission.

\section{Submission}

Three copies of manuscripts should be sent to the Publications Office, The Royal Society of Edinburgh, 22 George Street, Edinburgh EH2 2PQ, Scotland. Three copies of illustrations at publication size should also be submitted; for these sets, photocopies of line drawings are adequate, but not of photographs. Illustrations suitable for reproduction (see 3.1) may be requested subsequently. All submissions will be sent to two reviewers. Papers by more than one author must be submitted with a statement signed by each author, to the effect that the paper in its entirety is approved by the joint authors and naming the author who will be responsible for correspondence.

\section{Preparation of papers}

\subsection{Manuscripts}

Manuscripts should be on A4 $(295 \times 210 \mathrm{~mm})$ or quarto paper with double spacing throughout and wide margins. A title that is concise and informative, a heading of not more than 50 characters for use at the top of text pages and name(s) of author(s) are to be given on the first page. An abstract of not more than 200 words, intelligible without reference to the text or references, should be given on the second page, with a list of key words not in the title making up no more than 150 characters. The text should begin on the third page. Where possible, annotated illustrations and tables should be used in place of text. Give full postal address(es) at the end of the references. Tables and a list of figure captions should be on separate pages.

Editorial details. Words to be printed in italics, e.g. names of taxa, should be underlined. Use capital letters for formal terms only, in both text and headings. The metric system should be used throughout. Compass points are to be abbreviated to N, NW, NW-SE etc. Map references should be in square brackets, e.g. [NM 4437 0293]. Do not use footnotes except in tables. Examples of references in the text are: Jennings \& Smith (1967) record.... Bracketed references should be as follows: (James 1931), (Jennings \& Smith 1967, p. 132), (Jenkins 1947, 1950; Brock 1975). Indicate in the margins approximate positions for insertion of illustrations and tables. For particular treatment of palaeontological specialities consult PALAEONTOLOGY 15, 676-81.

\subsection{Headings}

The introduction section requires no heading. Primary headings, including Acknowledgements and References, are to be numbered 1., 2., 3. etc. (as in these Instructions) and secondary headings 1.1., 1.2., 1.3. etc.; these are to begin at the left-hand margin and should not be underlined. Show tertiary headings by wavy underlining. These should be indented and followed by a full-stop, four spaces and then the text of the sub-section. Cross-references in the text should be to a section or sub-section, e.g. (see 2.3), not to a page.

\section{Illustrations and tables}

\subsection{Illustrations}

Illustrations (Fig. 1, 2, 3 etc.) are printed within the body of the text. Where appropriate, group material into one figure and label $a, b, c$ etc. In the case of groups of photographs, labels and annotation should be on the appropriate photograph, not in the space between photographs. Please consider the size of lettering after reduction; it should not appear less than $6 \mathrm{pt}$. Large figures can be subdivided for reproduction on facing pages. Photographs should be high quality glossy prints with good contrast at final size and with a scale, or magnification in the caption. They should be mounted on white card, even if a black background is required in the published version (this requirement should be specified in an accompanying letter). In the case of fossil illustrations illumination should be top left. Originals of line drawings are usually required, either at publication size, or $\times 150 \%$, but high quality prints on matt paper at publication size may be acceptable.

\subsection{Tables}

Tables (1, 2, 3 etc.) will generally be set up in type and reproduced at column or page width, although certain tables are better presented using camera-ready copy prepared by the author; these should be submitted in the same way as line illustrations. Each table should have a heading and be on a separate sheet. For layout of analytical data see tables published in previous issues. Authors will be asked to send published analyses of igneous rocks to the UK-IGBA file.

\section{References}

Only published (or in press) items should be included in the References. Journal and series titles should not be abbreviated. References should be ordered thus: (1) Smith 1990, (2) Smith \& Brown 1997, (3) Smith \& Jones 1989, (4) Smith, Jones \& Clerk 1993, (5) Smith, Brown \& Clerk 1995, i.e. first author plus one should be in order of second author; et al. references should be in date order. Set out as indicated below:

Ahlberg, P. E. 1992. The palaeoecology and evolutionary history of the porolepiform sarcopterygians. In Mark-Kurik, E. (ed.) Fossil fishes as living animals. Tallinn: Academy of Sciences of Estonia, Institute of Geology.

Chappell, B. W. \& White, A. J. R. 1992. I- and S-type granites in the Lachlan Fold Belt. Transactions of the Royal Society of Edinburgh: Earth Sciences 83, 1-26.

Jarvik, E. 1980. Basic structure and evolution of vertebrates, Vol. 1, 74-98. London: Academic Press.

Zhuralev, A. Y. 1995. Preliminary suggestions on the global Early Cambrian zonation. In Geyer, G. \& Landing, E. (eds) Morocco 95. The Lower-Middle Cambrian Standard of Western Gondwana. Beringeria Special Issue 2, 147-60.

\section{Proofs and offprints}

One set of proofs will be sent to the author (or senior author of a joint paper). Ten free offprints (with covers) are provided and additional copies can be ordered when proofs are returned.

\section{Copyright}

On acceptance, authors will be asked to assign copyright of their paper to the Royal Society of Edinburgh. 


\section{TRANSACTIONS OF \\ THE ROYAL SOCIETY OF EDINBURGH: \\ EARTH SCIENCES}

Volume 89

1999 (for 1998)

Part 4

\section{Stuart CRAMPIN}

A successful stress-forecast: an addendum to 'Stress-forecasting: a viable alternative to earthquake prediction in a dynamic Earth'

E. R. PHILLIPS, R. A. SMITH and J. D. FLOYD

The Bail Hill Volcanic Group: alkaline within-plate volcanism during Ordovician sedimentation in the Southern Uplands, Scotland

Graham E. BUDD

The morphology and phylogenetic significance of Kerygmachela kierkegaardi Budd (Buen Formation, Lower Cambrian, N Greenland)

\section{B. J. BLUCK}

Clast assembling, bed-forms and structure in gravel beaches 